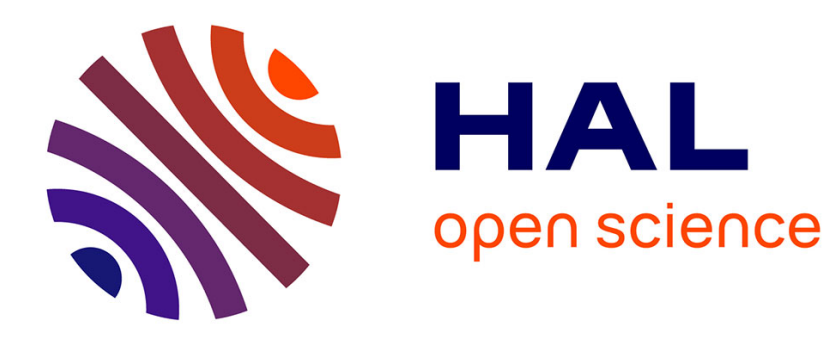

\title{
Mechanical properties of chromia scales
}

P. Tortorelli

\section{To cite this version:}

P. Tortorelli. Mechanical properties of chromia scales. Journal de Physique IV Proceedings, 1993, 03

(C9), pp.C9-943-C9-949. 10.1051/jp4:1993997 . jpa-00252439

\section{HAL Id: jpa-00252439 https://hal.science/jpa-00252439}

Submitted on 1 Jan 1993

HAL is a multi-disciplinary open access archive for the deposit and dissemination of scientific research documents, whether they are published or not. The documents may come from teaching and research institutions in France or abroad, or from public or private research centers.
L'archive ouverte pluridisciplinaire HAL, est destinée au dépôt et à la diffusion de documents scientifiques de niveau recherche, publiés ou non, émanant des établissements d'enseignement et de recherche français ou étrangers, des laboratoires publics ou privés. 


\title{
Mechanical properties of chromia scales
}

\author{
P.F. Tortorelli \\ Metals and Ceramics Division, Oak Ridge National Laboratory, Oak Ridge, 37831 Tennessee, \\ U.S.A.

\begin{abstract}
Depth-sensing submicron indentation testing was used to measure the elasticplastic behavior of sintered chromia and oxide scales formed on pure chromium in air. The use of top-down indentations limited the amount and precision of the scale data due to surface roughness and substrate effects. Nevertheless, results for the hardnesses and elastic moduli were within the range expected for such oxides. Within experimental uncertainty, the mechanical properties of the scales and those of the corresponding bulk oxide were generally comparable.
\end{abstract}

\section{Introduction.}

Knowledge of the mechanical properties of thermally grown surface oxides is of importance in assessing the ability of chemically stable scales to provide protection in corrosive, high temperature environments. Young's modulus is a key parameter in predicting the mechanical behavior of oxide scales (see, for example, Refs. [1-3]). It is needed for calculations of the critical strain for cracking and the fracture toughness parameter $K_{\mathrm{IC}}$, and, along with hardness, it is used to determine scale thickness limits for oxide yielding [3]. Therefore, mechanical characterization of scales has been of interest for many years. Methods to do such include traditional microhardness testing $[4,5]$, frequency damping measurements of elastic properties [6], acoustic emission detection of scale cracking [7, 8], and changes in bulk mechanical properties due to the presence of a surface oxide [9]. Recently, depth-sensing submicron indentation testing has been used to determine both plastic and elastic properties of chromia-rich scales on stainless steel [10] and alumina grown on iron aluminides [11] and was shown to offer several advantages, particularly in cases when the surface products are sparse or very thin. This paper presents results from a study of chromia scales formed on pure chromium, discusses some experimental obstacles, and evaluates whether scale data can be adequately represented by bulk oxide properties by examining companion results from indentations into sintered chromia.

\section{Experimental procedures.}

The hardness, Young's modulus, and plasticity of scales and bulk chromia were measured by depth-sensing submicron indentation testing using a mechanical properties microprobe (MPM) $[12,13]$. With the MPM, an indenter is forced into the surface of a specimen (via magnetic coupling) while its displacement is measured by a capacitance gage. The smallest loading increment is approximately $0.3 \mu \mathrm{N}$ (with a maximum load of $120 \mathrm{mN}$ ), and the displacement resolution is less than $1 \mathrm{~nm}$. A Berkovitch (three-faced) type of diamond indenter 
was used. With this, the lateral dimensions of an indentation were approximately $1 \mu \mathrm{m}$ for a $200 \mathrm{~nm}$ penetration. A light microscope is used to determine the area over which to place indentations, and indenter movements in all three dimensions are controlled by a computer, which is also used for data acquisition and analysis. Load and displacement are continually monitored during an indentation event and, from these data, hardness, elastic modulus, and plastic depth can be determined $[12,13]$. Hardness was derived by dividing the load at maximum displacement by the indenter contact area, which is determined from the indentation depth using an applicable geometric model for the tip shape [13]. The elastic moduli were determined from the slope of the initial unloading curve $[12,13]$.

The chromia scales used in this study were grown on pure electrolytic chromium at Harwell Laboratory (M.J. Bennett and A.T. Tuson) by exposure to oxygen at 850 and $950^{\circ} \mathrm{C}$. Several of the specimens were first implanted (at Harwell) with $2 \times 10^{16} \mathrm{Ce}^{+}$ions. Because such irradiations significantly reduce the rate of scaling [14], oxidation times were varied to obtain approximately the same amount of weight gain $\left(0.3-0.4 \mathrm{mg} / \mathrm{cm}^{2}\right)$ in each case. MPM data on both unirradiated (U) and implanted (I) chromium oxidized at $850(\mathrm{~L})$ and $950^{\circ} \mathrm{C}(\mathrm{H})$ were sought. However, the scale on an unimplanted chromium specimen that was oxidized at $950^{\circ} \mathrm{C}$ (UH) was sufficiently rough to make it impossible for the MPM to define the starting surface plane.

The mechanical properties data were obtained by direct top-down indentations into asgrown scales (attempted for UL, UH, and IH chromium) or taper-polished specimens (UL and IL conditions). The taper specimens were prepared at Harwell Laboratory (J.A. Desport) by careful polishing at a shallow angle with respect to the plane defined by the two long dimensions of the scale [15]. This procedure produces a polished outer surface where the original depth below the gas-scale interface varies as a function of the in-plane position in the direction of tapering [15].

To verify the validity of the MPM measurements of scale hardness and modulus, and to determine whether these properties might differ from those of the corresponding bulk oxide, a chromia ceramic was also characterized using the same submicron indentation technique. These measurements were made on a polished specimen of sintered chromia provided by J.-H. Park of Argonne National Laboratory.

\section{Results.}

As described above, indentations characterized by a complete load/unload cycle were made in three of the four types of oxidized chromium. However, only experiments with the UL and IH specimens yielded load-displacement behavior typical of an oxide-like material (and then just for a relatively small fraction of the indentations). Figure 1 shows that the behavior for a scale was clearly distinguishable from that of metallic chromium. The shape of the loadindentation depth curve for the scale (Fig. 1a) much more closely resembled that for bulk chromia (Fig. 1b) than that for the curve for chromium (Fig. 1c).

The ability to obtain indentation data was strongly affected by the amount and type of scale roughness. For the as-oxidized UL chromium, there were sufficiently large, relatively smooth areas of scale (between rather large hillocks) in which to successfully complete a small array of indenter loading cycles. On the other hand, no such sites were found on the unimplanted $950^{\circ} \mathrm{C}$ specimen and the MPM failed to yield any data. The dependence on surface finish was readily apparent from the results with taper-polished specimens, which presented a much smoother scale for indentation. In those cases (specifically for the $850^{\circ} \mathrm{C}$ unirradiated and implanted taper specimens), many indentations were made, but very few had the 


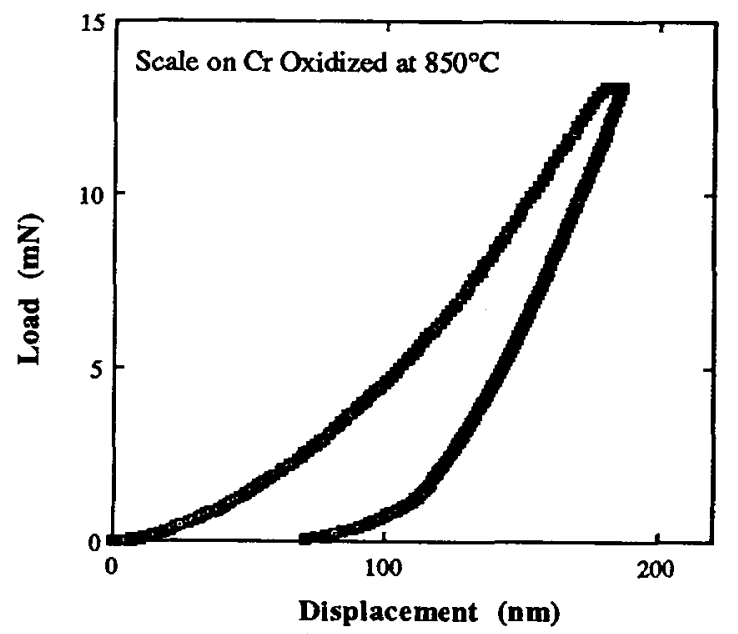

a)

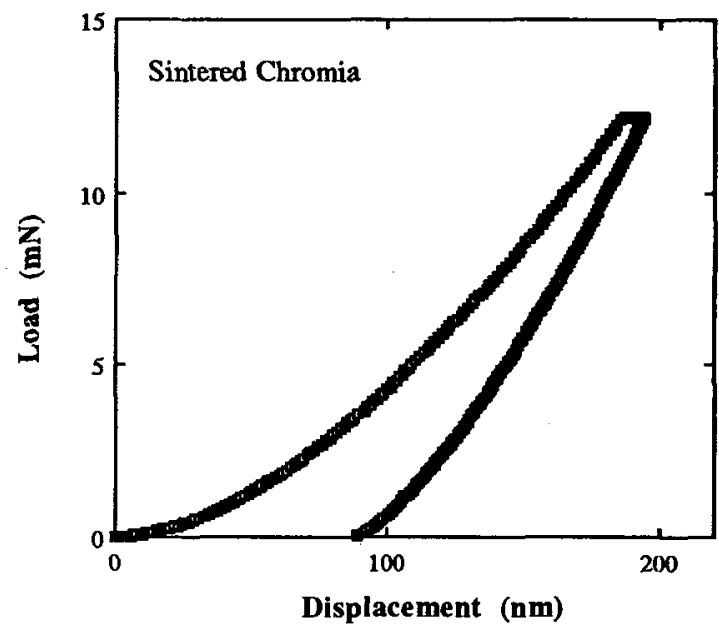

b)

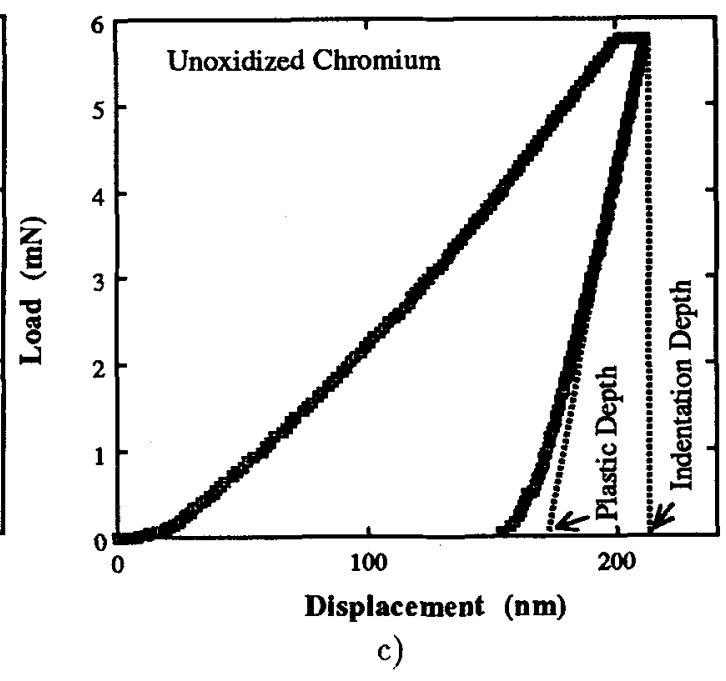

Fig. 1. - Load versus displacement using a diamond indenter: a) pure chromium oxidized in oxygen at $850^{\circ} \mathrm{C}$; b) polished sintered chromia; c) metallic chromium (indicating how plastic and indentation depths are determined).

loading/unloading behavior of a ceramic. For the unimplanted taper specimen, just a few indentations (out of more than 80 that apparently landed in the scale) yielded results that were consistent with a hard ceramic. Despite many indentations into an apparent scale on a taper-polished IL specimen, none of the resulting data gave an unambiguous indication that a surface oxide was present.

The average values of hardness, elastic modulus, and ratio of plastic to final indentation depth $(P D / I D$, see Fig. 1c), and their respective standard deviations, are listed in table I for the cases in which oxidized specimens showed MPM evidence of a harder surface layer. The results for sintered chromia and unoxidized chromium are also included. Only five oxide-like 
loadings were obtained for the scale on the IH specimen; the reported averages should be therefore treated as very preliminary. Despite significant porosity, the polished bulk chromia specimen had sufficiently large areas of dense material relative to the lateral resolution of the MPM so as to yield a high fraction of successful indentations with relatively little scatter. The chromium data were taken from indentations into the part of a taper-polished specimen where all the scale had been removed.

Table I. - Hardness, elastic modulus, and ratio of plastic to total indentation depth ( $P D / I D)$ for oxidized and metallic chromium and bulk sintered chromia.

\begin{tabular}{|l|c|c|c|}
\hline Specimen $\left(^{\mathrm{a}}\right)$ & Hardness (GPa) & Modulus (GPa) & $P D / I D$ \\
\hline $\mathrm{UL} \mathrm{Cr}$ & $29 \pm 7$ & $272 \pm 62$ & $0.65 \pm 0.04$ \\
$\mathrm{UL} \mathrm{Cr}(\mathrm{t})$ & $21 \pm 4$ & $165 \pm 19$ & $0.63 \pm 0.03$ \\
$\mathrm{IH} \mathrm{Cr}(\mathrm{b})$ & $21 \pm 3$ & $327 \pm 88$ & \\
$\mathrm{Bulk} \mathrm{Cr}_{2} \mathrm{O}_{3}$ & $37 \pm 4$ & $273 \pm 17$ & $0.60 \pm 0.02$ \\
$\mathrm{Gr}$ & $6 \pm 1$ & $129 \pm 5$ & $0.83 \pm 0.01$ \\
\hline
\end{tabular}

(a) U: unimplanted; I: implanted with Ce ions prior to oxidation; L: oxidized at $850^{\circ} \mathrm{C}$; $\mathrm{H}$ : oxidized at $950^{\circ} \mathrm{C}$; t: as-oxidized surface with taper-polish.

$\left({ }^{b}\right)$ Averages from only five indentations.

\section{Discussion.}

Because the present technique is limited to room temperature indentations, there is a valid concern about the relevance of these measurements for scales whose performance is judged at elevated temperature. When reporting traditional microhardness data on scales, Wood and Hodgkiess [4] argued that, given the state of knowledge regarding the mechanical behavior of oxide scales, any attempt to measure relevant properties, even at room temperature, has some value. This situation still appears to be valid despite some progress in the intervening twenty years and, in view of the recent ability to conduct depth-sensing indentation on a submicron scale (and derive both hardness and modulus data), the advantages of such measurements for thin oxide scales appear well worth examining.

In previously reported MPM work with oxide scales [10, 11], indentations were made into polished cross sections of oxidized specimens. Because the surface oxides were rather thin, it was difficult to assure indentation into the actual scales despite the small dimensions of the indenter (principally due to thermal drift). However, when the targeting was successful, quite reasonable values for scale hardness and modulus were found $[10,11]$. The present top-down approach to scale measurements avoids the problem of limited target area by indenting in the direction parallel to the principal growth dimension of the scale. However, the depth sensitivity of the MPM requires relatively smooth surfaces (so the instrument can accurately define the surface plane and the indenter can clear any asperities) and, as described above, oxide scales are often sufficiently rough to render the submicron indentation process inoperable. 
The effect of surface morphology on the indentation process is of particular concern for chromia grown on pure chromium because of the well-known tendency for such scales to be rough and defective [16]. This complication can possibly be avoided by measurements on chromia-formers containing oxygen-active elements, such as thoria-dispersed nickelchromium [17], which form more uniform scales (albeit often by a different growth mechanism) [16]. As shown by the present results, polishing the oxide surface did eliminate the problems related to surface roughness. However, none of the load-displacement data was characteristic of a hard ceramic for the taper-polished IL specimen and the average property values gotten from a fraction of the indentations into the similarly prepared UL specimen were lower than both the unpolished specimen and bulk chromia, particularly for the modulus (see Tab. I). These results may be explained by the fact that, in top-down indentations, the metal substrate can influence the measurement of both hardness and modulus if the total displacement exceeds 15 to $25 \%$ of the scale thickness [18]. For the relatively thin chromia scales of this study, the indenter at maximum displacement $(200 \mathrm{~nm})$ certainly exceeded these limits in the thin parts of the taper-polished scales. Thus, measured values that fall somewhere between those of ceramics and metals, as was the case for the taper-polished UL specimen, are not unexpected. The measurement of Young's modulus is even more sensitive to the presence of the substrate $[12,18]$ and, as seen in table I, the measured scale modulus of this UL specimen was much more like that of chromium than the hardness. Therefore, there appears to be an appreciable substrate effect for taper-polished specimens. This problem, and that of surface roughness, offset the advantage of top-down indentations (larger indenter target and, for as-oxidized surfaces, the avoidance of polishing effects) relative to those for polished cross sections (at least in the present case).

Table II. - Comparison of MPM scale data for chromia on chromium with other results.

\begin{tabular}{|l|c|c|}
\hline Approach & $\begin{array}{c}\text { Hardness } \\
(\mathrm{GPa})\end{array}$ & $\begin{array}{c}\text { Modulus } \\
(\mathrm{GPa})\end{array}$ \\
\hline MPM-this study, UL & 29 & 272 \\
MPM-this study, IH & 21 & 327 \\
MPM-chromia on steel [12, 20] $\left(^{\mathrm{a}}\right)$ & 23,25 & 280,296 \\
Microhardness-chromia on Fe-Cr alloys [4] & $18-33$ & -- \\
Robertson and Manning estimates & & \\
from literature [3] & 15 & 280 \\
\hline
\end{tabular}

(a) Data analyzed as an average over a range of indenter depths.

Initial indications of the appropriateness of this submicron indentation method have previously been reported $[10,11]$. In the present case, despite the limitations imposed by scale roughness and substrate effects, the values of hardness, modulus, and relative plastic depth measured for chromia scales are certainly within the range expected for ceramics, particularly in view of all the possible factors (surface preparation, impurities, crystallographic effects, etc.) that can contribute to variations in hardness and/or modulus [19]. As shown in table II, the hardness and modulus are close to those measured for chromia-rich scales on stainless steel $[10,20]$ and all the hardness values fall within the range measured by Wood and Hodgkiess 
[4]. Furthermore, the present MPM determination of Young's modulus for bulk chromia $(275 \mathrm{GPa})$ agrees quite well with a literature value $(286 \mathrm{GPa})$ [3], as well as with those from previous measurements for chromia-rich scales on stainless steel (280 to $300 \mathrm{GPa}$ ) [10]. It is interesting to note that the experimental uncertainty is significantly greater for the scale measurements than for those on the bulk chromia and metallic chromium (Tab. 1). This is partially due to the lack of many indentations in the scale and, therefore, there is potential for reduction in variability by technique improvements that increase the fraction of successful loadings. However, the scatter in the data also reflects property and thickness variations within the scale as well as influence of defects [10].

The extent to which bulk oxide data is adequate for describing the mechanical properties of corresponding scales can be examined by direct comparison of MPM data for scales on chromium and that for sintered chromia. Notwithstanding that measurement on scales may be easier than testing bulk ceramics (and the difficulty of matching compositions of the two oxide forms in some cases), it is important to determine whether the data base for oxides can be exploited to predict scale behavior. In their calculations of scale fracture conditions, Robertson and Manning [3] opted to use values of Young's modulus, surface fracture energy, and yield stress (hardness) derived principally from bulk oxide data (modified to account for porosity and microstructure) because of concern with errors associated with measurements on scales. They argued that scale values of Young's modulus should be similar or slightly less than those of the corresponding bulk oxide [3]. However, recent MPM data for alumina [11] showed that the hardness and modulus of scales did not always match that of bulk $\mathrm{Al}_{2} \mathrm{O}_{3}$. In the present study, the uncertainty associated with MPM measurements for chromia on chromium (Tab. I) prevents any strict differentiation between bulk and scale properties of $\mathrm{Cr}_{2} \mathrm{O}_{3}$. (As discussed above, the data for the taper-polished UL specimen reflects the influence of the chromium substrate and is excluded from the present discussion.) Although there is no statistically significant difference among the average $P D / I D$ values, the scale plasticity aspect can also be addressed by examining $E / H^{2}$ because a scale can fail in a ductile manner by yielding (rather than by brittle cracking) if its thickness is less than a critical value that is proportional to this ratio [3]. Values of $E / H^{2}$ obtained from the present data indicate that there is an overlap (albeit small) of the experimental uncertainty associated with the bulk $\mathrm{Cr}_{2} \mathrm{O}_{3}$ value with that for the scale on the UL specimen, but not with the range for the oxidized IH chromium (which had a higher average ratio). This would imply greater plasticity of the latter specimen relative to the bulk oxide. Unfortunately, as described above, the extremely small number of indentations used for the $\mathrm{IH}$ measurements makes any conclusion based on its results very preliminary.

\section{Summary and conclusions.}

A mechanical properties microprobe (MPM) was used to measure hardness, Young's modulus, and plasticity on oxidized chromium and sintered chromia by depth-sensing submicron indentation testing. The roughness of the scales limited the amount of data obtained by top-down indentation and was partially responsible for relatively large uncertainties in the determination of hardness and modulus. For the thinner scales, substrate effects interfered with accurate measurement of scale properties. Despite these experimental difficulties, the present work showed that the MPM can generate reasonable mechanical properties data for thin chromia scales. There is some potential for reduction in scale data variability in topdown indentations if techniques to increase the fraction of successful loadings are developed. This study also demonstrated the importance of having companion data on the bulk form of 
the scale oxide. Within experimental uncertainty, the hardness and modulus of the chromia scales and those of the bulk $\mathrm{Cr}_{2} \mathrm{O}_{3}$ were the same, although there was a tentative indication that one of the scales may exhibit greater plasticity.

\section{Acknowledgements.}

Research sponsored by the Fossil Energy AR\&TD Materials Program, U S. Department of Energy, under contract DE-AC05-84OR21400 with Martin Marietta Energy Systems, Inc. The author wishes to thank J.H. DeVan, J.R. DiStefano, and J.R. Keiser for their reviews of the manuscript and gratefully acknowledges the preparation and supply of specimens by M.J. Bennett, J.A. Desport, and A.T. Tuson of Harwell Laboratory (United Kingdom) and J.-H. Park of Argonne National Laboratory (U.S.A.).

\section{References}

[1] EvanS H.E., LobB R.C., Corros. Sci 24 (1984) 209.

[2] HaNCOCK P., NichOlls J.R., Mater. Sci. Technol. 4 (1988) 398.

[3] Robertson J., Manning M.I., Mater. Sci. Technol. 6 (1990) 81.

[4] WoOD G.C., HodGKIEsS T., Werkst. Korros. 23 (1972) 766.

[5] WestbrooK J.H., Rev. Hautes. Temp. Refract. 3 (1966) 47.

[6] BRUCE D., HaNCOCK P., J. Inst. Met. 97 (1969) 140.

[7] BENNETT M.J. et al. AERE R 13685, UKAEA Harwell Laboratory report, (Dec. 1989).

[8] Tiefan L., Meishuan L., Mater. Sci. Eng. A120 (1989) 239.

[9] SCHutZe M., Mater. Sci. Eng. A121 (1989) 563.

[10] TORTORELli P.F. et al., Microscopy of Oxidation, M.J. Bennett, G.W. Lorimer Eds. (The Institute of Metals, London, 1991) p.271.

[11] TORTORELli P.F., KeISER J.R., Scr. Metall. Mater. 25 (1991) 2339.

[12] NIX W.D., Metall. Trans. A 20A (1989) 2217.

[13] OLIVER W.C., PHARR G.M., "An Improved Technique For Determining Hardness and Modulus Using Depth Sensing Microcontact Experiments", accepted for publication in J. Mater. Res. (June 1992).

[14] BENNETT M.J. et al., Mater. Sci. Eng. 69 (1985) 359.

[15] BenneTt M.J., DESPORT J.A., "Surface Microsurgery: Taper Section Preparation," this volume.

[16] KOFSTAD P., High Temperature Corrosion (Elsevier Applied Science, London 1988).

[17] WRIGHT I.G., Battelle Memorial Institute, private communication (May 1991).

[18] MChargue C.J., Diamond and Diamond-Like Films and Coatings, Vol. 266, R.E. Clausing et al. Eds. (NATO-Advanced Study Institute Series B: Physics, Plenum Press, New York, 1991).

[19] MCCOLM I.J., Ceramic Hardness (Plenum Press, New York, 1990).

[20] TORTORelli P.F. et al., Proc. Fourth Annual Conf. Fossil Energy Materials, ORNL/FMP-90/1, Conf. 900546 (U.S. Department of Energy, August 1990) p.463. 